\title{
Universities as Drivers of the Urban Economies in Asia: The Case of Vietnam
}

\author{
Tran Ngoc Ca ${ }^{1}$
}

National Institute for Science and Technology Policy and Strategy Studies

\begin{abstract}
This study looks at the contribution of the university system in Vietnam to the socioeconomic development in general, and their relationship with firms, dynamic actors of the economy in particular. The study uses different methods of research, from reliance on secondary data to interviews with universities and survey of firms. Several case studies of the key universities in four regions have been undertaken: Hanoi in the north, Danang in the center, and Ho Chi Minh City and Cantho in the south of Vietnam. The findings show that the role of Vietnamese universities in research is much weaker than teaching, and that their contribution to the socioeconomic development of the country is limited to the production of an educated labor force rather than innovation. However, in selected universities, innovation did take place to a certain extent and brought benefits for both the universities and firms they served. This situation is explained by both the inheritance of the previous build up of the university system in Vietnam and its shift in behavior in the context of economic renovation and globalization.
\end{abstract}

World Bank Policy Research Working Paper 3949, June 2006

The Policy Research Working Paper Series disseminates the findings of work in progress to encourage the exchange of ideas about development issues. An objective of the series is to get the findings out quickly, even if the presentations are less than fully polished. The papers carry the names of the authors and should be cited accordingly. The findings, interpretations, and conclusions expressed in this paper are entirely those of the authors. They do not necessarily represent the view of the World Bank, its Executive Directors, or the countries they represent. Policy Research Working Papers are available online at http://econ.worldbank.org.

${ }^{1}$ With collaboration of Le Van Chuong, Nguyen Phuong Mai, Nguyen Do Anh Tuan, NISTPASS. The authors also would like to thank staff of universities and firms for providing data and interviews.

1 


\section{INTRODUCTION}

In an effort to achieve the Millennium Development Goals (MDGs), the Vietnamese government has assigned high priority to education (UNDP, 2003), including at the tertiary level. Previous studies of the impact of universities in Vietnam have focused primarily on their role in generating income and jobs through their own and their students' expenditure within the regions where they are located. However, the potential impact of universities is not limited to these backward linkages: there are potential forward linkage effects as well. These include the supply of skilled workers, but also industry-university research collaboration and consultancy services for local firms. In Vietnam, the extent that business-university collaboration has benefited local (urban) economies in general, and firms in particular, has not been studied in sufficient detail.

This article situates the role of universities in Vietnam's development in the context of increased challenges and opportunities brought about by globalization. The study examines the characteristics of universities and the context that shapes their roles; the current extent and modes of collaboration between universities and firms; and institutional barriers hindering ties between universities and firms. We find that Vietnamese universities have contributed significantly to the development of local areas, though for the most part this has been through the supply of human resources rather than through job creation or the creation of new enterprises.

Our findings result from a review of secondary literature, interviews with Vietnamese firms and selected case studies devoted to the policy and institutional environments in Vietnam. The next section of the article provides an overview of the 
Vietnamese context and the role of universities in the country's innovation system. Case studies of four universities are then provided in order to offer a more comprehensive picture of variation across specific contexts. The article concludes with consideration of policy interventions that could encourage universities to make greater contribution to the Vietnamese economy's competitiveness in the global market.

\section{VIETNAM'S INNOVATION SYSTEM AND THE ROLE OF UNIVERSITIES}

To map the context in which universities operate, it is useful to provide an overall picture of Vietnam's economy in general and innovation system in particular. Vietnam is experiencing multiple challenges of globalization: it must increase the competitiveness of

its economy and pursue industrialization and modernization while joining international economic institutions and regimes. Thus, the country is undergoing a double transition, from a planned economy to a market-oriented system and from an inward-orientation toward greater regional and international economic integration. Vietnam remains an agricultural economy and society, with three-fourths of the population living in rural areas and two-thirds of the labor force still working in an agricultural sector characterized by low productivity. Economic backwardness and weakness are revealed by very low levels of efficiency and competitiveness.

The structure and characteristics of the economy shape the kinds of knowledge, technologies and R\&D activities needed to upgrade production capabilities. Models of university-industry linkage (UIL) should therefore be examined in close interaction with local context. At the same time, changes in the policy and market environments 
influence the behavior of universities and the extent of their interaction with firms. As our case studies demonstrate, these shifts tend to be location specific rather than generic.

It is worth noting that until recently both state enterprises and private firms have experienced limited need for technology innovation due to a longstanding absence of competitive pressure. Largely for this reason, the R\&D and learning capabilities of firms have been weak. It has been difficult for economic actors to link to knowledge institutions to develop joint research activities or product innovation. The sole exception is in the few industries, such as telecom and energy (oil and gas, power generation), where the rate of innovation is higher and relatively high levels of investment resources are available.

Vietnamese exports began with basic primary products like rice, shrimps and cashew nuts, and have moved gradually to manufactured goods such as textiles, garments, footwear and electronics. This shift requires manufacturing technology that can help firms in dealing with quality and other technical standards of international markets. The abolition of trade protection in the framework of regional agreements such as the Association of Southeast Asian Nations (ASEAN), the Asia Free Trade Association (AFTA), and the BTA will lead eventually to the same competitive conditions for the domestic market.

Certainly, both training and R\&D provided by universities have to serve the production needs of firms. By all accounts, the inadequate supply of a skilled labor force is an especially urgent matter. Local enterprises often complain about the difficulties in finding enough skilled labor force for their production activities (Pham Minh Hac, 2000), and the traditional mandate of universities in Vietnam is to 4 
produce human resources rather than to engage in research. ${ }^{1}$ Although this mandate has changed over the last decade, with more emphasis being placed on $R \& D$, the role of universities in the national innovation system arguably should be examined more in terms of training than on advancement of innovation capabilities. The general context of Vietnamese production points to the need for an innovation system and universities capable of serving medium-tech firms. At the same time, universities still have to carry on with the traditional mandate, that is, provision of labor force, first for domestic enterprises and then for firms resulting from FDI.

Socio-economic transformations of the last 20 years have created an impetus for changes in the higher education system in order to contribute to the creation of a new generation of the workforce. Fees for training activities also have brought substantial extra resources for universities. At the same time, many universities have begun to overcome their old mode of operation, in which teaching was divorced from research, by becoming involved in R\&D projects and pilot production. Between 1991 and 1996, universities undertook nearly 200 pilot production projects relying on their own research results and contracting systems. From 1996-2002 universities implemented 3,800 R\&D projects and were involved in 90 pilot production projects. By the end of 2002, the university system encompassed 167 research divisions and 147 centers dealing with technology development and consulting activities.

As depicted in Table 1, however, the bulk of R\&D activities are conducted not in universities but in research institutes under line ministries and in two national research centers devoted to natural and engineering sciences and social sciences 2 . There is very modest financing of R\&D via the state budget: Vietnam spent around $0.5 \%$ of its GDP on 
R\&D in 2003 (Asian Productivity Association, 2003), whereas in most OECD countries and China around 2\% of GDP is devoted to this purpose. Moreover, most publicly funded R\&D is conducted in government research institutes. Only a limited number of university faculties have adequate resources for significant R\&D. The research infrastructure is below international standards, and what research is being carried out tends to be theoretical, supply-driven, and not connected to the needs of the productive sector. The national R\&D system is "organized, financed and managed in such a way that technology transfer is difficult and expensive" (Bezanson et al., 2000).

Table 1: R\&D Personnel Comparisons in 1990-2001

\begin{tabular}{|l|l|l|l|l|}
\hline \multirow{2}{*}{$\begin{array}{l}\text { Country } \\
\text { R\&D personnel } \\
\text { per 1 million } \\
\text { people }\end{array}$} & $\begin{array}{l}\text { GDP } \\
\text { (billion USD) }\end{array}$ & $\begin{array}{l}\text { Population } \\
\text { (millions) }\end{array}$ & $\begin{array}{l}\text { Rersonnel } \\
\text { per billion } \\
\text { USD of } \\
\text { GDP }\end{array}$ \\
\hline Vietnam & 274 & & & 629 \\
\hline China & 584 & 35.1 & 80.3 & 597.3 \\
\hline Korea & 2,880 & $1,266.1$ & $1,294.9$ & 286.4 \\
\hline
\end{tabular}

Source: Calculated from UNDP Human Development Report Statistics 2004, http://hdr.undp.org/statistics/data

According to MOET data, in 2000 Vietnam had 77 universities and 114 colleges, housing 160 institutes and research centers. Total teaching staff was 55,887, of which 35,938 were lecturers with university degrees and above. Until the beginning of 2003, the 
country had two national universities, three regional universities (with 20 university members), 76 independent universities and academies and 119 colleges. Among these, there were two semi-private and 16 private universities, and four semi-private and three private colleges. During academic year 2004 - 2005 the number of universities and colleges had grown to 230 (93 universities, and 137 colleges) (MOET, 2005). Tertiary education gross enrollment was 8.6\% in 2001, up from $1.5 \%$ in 1992 and a total of 1.3 million graduates have attended technical training institutes ${ }^{3}$.

Over the last few years, the infrastructure and facilities of the university system have been upgraded significantly. Some laboratories have reached the regional standard. The system of electronic libraries and electronic communication networks such as LAN, have been strengthened, and websites have been set up. Expenditure for the R\&D activities of universities is about $4 \%$ of total investment for national science and technology. Apart from the government budget, which satisfies about $50 \%$ of the need for science and technology activities, many universities have been contracted by other organizations and received non-government sources of funding: 29.2\% from enterprises; 6.7\% from other organizations and $48.8 \%$ from international sources.

\section{FIRMS AND UNIVERSITIES: DEMAND VERSUS SUPPLY}

Looking at firms, there is a mixture of various kinds of actors in the Vietnamese economy. A majority of local firms are still small and medium enterprises (SMEs). In an innovation survey (Nguyen Vo Hung \& Nguyen Thanh Ha, 2004) covering the mechanics and food processing industries, a majority of firms reported having innovation ideas from their own activities (82.4\%) and from 
suggestions of customers (58.8\%). These innovations are not significant or breakthrough in nature but rather incremental and minor. With this type of innovation, the supplier-producer-customer linkage is more important for technology learning than is the linkage with public institutions such as R\&D institutes.

If the small firms tend to have innovation ideas from their own activities and customer suggestions, big firms like state corporations under key ministries seem to have a more diversified source of ideas for innovation. Public institutions such as R\&D institutes and tech-info centers play a limited role in the learning activities of these firms. Instead, cooperation with domestic, foreign and FDI partners are considered important channels to address problems that firms face in the innovation process. The aforementioned innovation survey found that $71 \%$ of SMEs and $93 \%$ of non-SMEs in the mechanics sector reported having relationships with foreign/FDI firms. This means that large corporations usually have more resources for innovation and R\&D and a larger window for learning than SMEs have.

Many obstacles and disincentives prevent or discourage SMEs from developing innovation capabilities, and the limited amount of innovation that does take place in SMEs is concentrated in process development and quality control. Firms do not have sufficient resources for long-term investments, including recruitment of highly skilled labor and equipment to innovate. Technical services are unavailable to small firms, which typically lack information on available technologies. Market barriers are also high, as SMEs are unaware of product requirements and distribution channels. Finally, "SMEs have a hard time obtaining credit from banks due to a lack of collateral assets and because of the complicated 8 
procedure of getting credit" (Bezanson et al., 2000). Moreover, private enterprises are at a disadvantage as compared to SOEs, due to their lack of access to both preferential and non-preferential government loans. They must rely on their own capital resources for $\mathrm{R} \& \mathrm{D}$.

Figure 1 R\&D Source Distribution in Enterprises in 2002

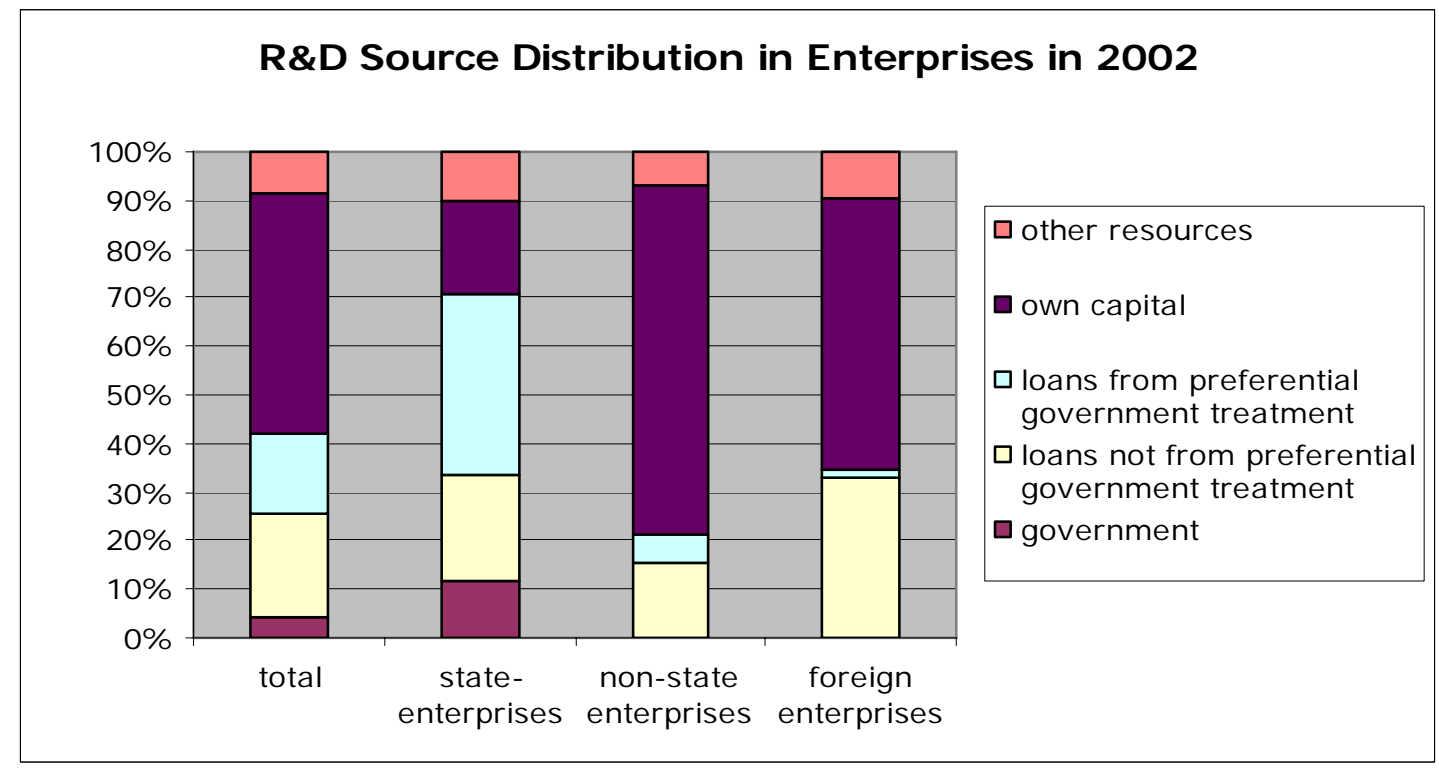

Source: General Statistics Office 2004

Although a range of studies ${ }^{4}$ have pinpointed a need by firms for technological services for innovation, this is not met at this juncture by $R \& D$ organizations and universities. The situation is much worse outside of Hanoi and Ho Chi Minh City, where there is complete lack of supply for some services (Miehlbrandt, 2002).

Among research institutes and universities, the share of cooperation with enterprises is low. As depicted in Table 2, a survey of linkages between R\&D institutes, universities and industries reveals that universities are doing even less cooperation with firms than research institutes are. 
Table 2. Contracts with enterprises per total projects and funding

\begin{tabular}{|l|l|l|}
\hline & $\begin{array}{l}\text { Share in number of } \\
\text { research projects }\end{array}$ & $\begin{array}{l}\text { Share in value of } \\
\text { research funding } \\
(\%)\end{array}$ \\
\hline Research & 17 & 35 \\
\hline Institutes & & \\
\hline Universities & 6.1 & 28 \\
\hline
\end{tabular}

Source: NISTPASS, 2000

FDI firms are strongly concentrated in the manufacturing sector, chiefly in light industries. Few investors are in service industries and at this stage there is little FDI in high-tech sectors. Regardless of the extent to which FDI has accounted for technological advancement of local industries, it is the general consensus that S\&T institutions have not done much to support these gains. NISTPASS (1997) observed that the production sector considers that S\&T institutions cannot provide necessary support for their production problems. NISTPASS (2000) also found that S\&T institutions had few contracts from the production sector in the period from 1995 to 1998, and that the type of contracts that did exist were small scale, simple and low-risk in nature.

As we can see from this section, different types of firms exhibit different behavior and extent of engagement with regard to innovation. The SME sector in general is weak and sources its $R \& D$ externally, relying little on $R \& D$ institutions and universities. Large corporations are in somewhat better position to do the same. FDI firms tend to rely on 
their home country R\&D organizations. Taken as a whole, what this suggests is that there are few opportunities for Vietnamese R\&D institutions and universities to play a significant role in helping firms, and even when they do, these activities involve mainly incremental and minor technical change.

If the demand side is limited, it is not surprising that universities' share in R\&D supply is not high. In terms of infrastructure and other teaching and R\&D facilities, although there is some investment for upgrading lately, this tends to be restricted to the largest universities. Many universities still use equipment and facilities in place since the mid-1960s or 1970s. Libraries in many universities are small, outdated in both quality and holdings. Foreign languages literature is still mainly in Russian, dating back to the mid-1970s. Even for those universities with access to English language literature, the rate of use is minimal due to low English capability of the staff and overload of teaching. As a result, teaching curricula are old, repetitive and lacking in innovative approaches and new knowledge. Moreover, there has been a lack of electronic links with a national library or central information and librarian system.

On the training side, enterprises rely on unskilled and semi-skilled labor and maintain low productivity levels. Enrollment in vocational institutions is low or consists of short-term training, while informal education plays an important role in acquiring skills (UNIDO, 1999). Many firms are able to maintain or improve production in export markets by investing in training their workforce, yet most staff training focuses on shortterm needs. Firms do not train staff at higher technical levels due to a lack of resources and the risks involved in losing staff to competitors offering better working conditions. Although Vietnam has a high literacy rate (94\%) through its implementation of near- 
universal primary education and its long tradition of learning, access to technical training and higher education institutions has been limited, and the skill level of the workforce is insufficient for technology development. Universities in general are mandated mainly to produce students, but all too often their graduates lack practical expertise. Data from the aforementioned empirical study also reveal information concerning the status of linkages between R\&D, postgraduate education and the needs of the economy and the production sector (NISTPASS, 2000):

- Universities contributed actively to the training needs of the society and economy. However, direct service to enterprises has been insignificant.

- There is an enduring imbalance between the subject of study and firm needs. Most postgraduate students are in social sciences and humanities, while those subjects closer to productive activities -- like engineering or agro-forestry sciences and technologies -- remain comparatively underdeveloped.

- The majority of organizations sending their staff for university training consist of government agencies, whereas very few programs result from the needs of productive enterprises.

- Links between industries and research institutes are not close. There has been lack of a system of brokerage organizations to deal with bridging R\&D and production activities. Coordination of research activities between R\&D institutes and enterprises is very weak or almost absent.

- Research capability of enterprises is very weak and negatively influences the development of university-industry linkages. 
This situation is related largely to problems faced by the current R\&D system. Most Vietnamese universities are not perceived as centers of R\&D excellence. They lack autonomous status, and despite the fact that their operations have been increasingly independent, they still receive many directives from above and operate under regulations of MOET. Especially in public universities, staff faces constraints in terms of salary ceilings, human resource management regulations and financial incentives. Basically, they are still seen as government officials rather than as academics.

Lack of macro incentive regimes has discouraged motivation and dynamism for teaching staff in universities. There are no incentives encouraging them to interact with other institutions and the firms. To date, cooperation between university staff and units outside the university system has been short term, based mainly on personal and informal connections. Besides training of a higher-skilled labor force, the contribution of university activities as such tends to be of a one-off nature. In the existing system, universities do not see technology transfer activities as crucial for their existence and they are not very attractive to the firms as a source of innovation and new knowledge. In many instances, technology facilities and innovation rates in universities are substantially behind those of firms.

Concerning human resources for teaching, the number of professors and lecturers is inadequate given the number of students ${ }^{5}$. Between 1995 and 2005, for instance, student enrollment increased 4.43 times (from 297,900 to 1,319,754 students), while teaching staff increased by less than half that amount (from 22,750 to 47,616 lecturers) ${ }^{6}$. Given this overload of teaching, there is little time for staff to engage in research and technology development or other learning activities. Teaching staff in Vietnamese 
universities reflect a generalized problem of ageing throughout the science and technology system. The majority of full and associate professors are above 55 years old, and there are insufficient replacements in the pipeline. This is likely to lead to a generational gap in human resources of the university system in the near future. Notwithstanding isolated exceptions, there has been no entrepreneurial spirit among academics working in universities. The most entrepreneurial character so far is reflected in the desire of teachers to do "outside the class" teaching to earn extra money. This is explainable by the low base salaries of academic staff and their need to earn second or third incomes through various teaching and consulting assignments.

As seen in this section, the linkages between universities, research institutes and enterprises in general, and between universities and firms in particular, still face many hurdles that undermine university attempts to better serve the needs of the local economies where universities are located. The view from firms, reflected in various surveys, confirms that there is a demand for technology and training services provided by R\&D institutes and universities. However, the demand has been hardly met, and the extent of relationship of firms with universities is less than satisfactory. In this context, the contribution of R\&D and training institutions in general and of universities in particular is below the desirable level.

\section{CASE STUDIES OF FOUR UNIVERSITIES}

\section{HANOI UNIVERSITY OF TECHNOLOGY (HUT)}

Hanoi University of Technology (HUT) was established by government decree on March 6, 1956 as the first university of the Democratic Republic of Vietnam. Today 14 
HUT consists of 14 faculties and 25 institutes and centers. It has 1,800 staff, including 1,500 lecturers and 240 professors and associate professors, 450 of whom possess doctorates. The university annually enrolls 35,000 undergraduate and 2,000 graduate and postgraduate students. With teaching as its core mandate, skills development constitutes the main type of cooperation between HUT and local enterprises. The HUT gives support to firms through training and re-training of staff and upgrading of technological expertise. Contracts for technical services and other R\&D activities for firms represent another kind of university linkage with industry, and HUT also provides firms with consultancy services on technology innovation and equipment upgrading.

To develop outreach to local enterprises, the university has created several incubators for technology and business development. Funding for R\&D comes from three main sources: the state budget for programs and projects, the business sector through contractual arrangements, and international organizations via development assistance. In general, however, the quality of research in HUT is still low, and research projects are seldom linked to needs of the productive sector.

Yet in some cases technology transfer from HUT to local organizations has been noticeable. In a range of engineering subjects, such as new material technology, polymer and composite technology for electrical, electronics and bioengineering, HUT has been doing research to create applications in such fields as transport, agriculture, aquaculture, environment protection, telecom, automation and power generation. Interestingly, it is a policy of the HUT not to encourage staff to work individually with outside firms. Instead, HUT has set up a company, Polynco, as a centralized commercial arm of the 
university to deal with all technology transfer needs. Today Polynco is self-financing, and earns income from technology transfer contracts.

A number of policy and legal provisions have been designed to promote creation of companies from within the university. These are excessively vague, however, and regulations for implementation are not in place. The absence of communication mechanisms is another obstacle to strengthened linkages between university and companies. There is no system of match making or brokering to bridge the gap between the technology that the university has to offer and the needs of firms that are potential users of that technology. The government is working on the development of technology market mechanisms ${ }^{7}$ by creating technology transaction floors in selected cities or Techmart. Post-techmart supporting measures have been undertaken to follow up sales and transactions. So far the initial costs for organizing these events are covered by the MOST from its S\&T central budget. In the near future, the newly established National Science and Technology Foundation may cover a portion of the expense for this activity. This move has facilitated quite actively the linkage between research institutions like HUT and local firms.

Apart from policies promoted by central government, Hanoi city itself seems to have less initiative and dynamism. The city office of the Department of S\&T has launched some programs to develop technology markets, but with little impact on innovation and without success in fostering closer collaboration between HUT and firms. Where relationships with firms exist these derive mainly from the highly entrepreneurial leadership of HUT, which has set up its own firms to deal with technology 
commercialization and tends to use its own connections with people in the central government rather than in the Hanoi government.

Another issue on the municipal agenda is setting up a Hanoi high-tech zone. A consultant group had recommended that the focus should be put on existing strengths of HUT in Dai Co Viet street (where the HUT campus is located), in an effort to turn it into high-tech corridor. But this proposal did not receive significant attention. Instead, another corridor was set up to the northwest of Hanoi, with investment from foreign firms leading to the creation of the Hanoi International Technology Center (HITC). Subsequently, the central government decided to set up a large (national) high-tech park in Hoa Lac, about $40 \mathrm{~km}$ west of Hanoi. The lack of coordination between central and municipal authorities has impeded somewhat HUT's efforts to become a hub for innovation in the city.

\section{DANANG UNIVERSITY OF ECONOMICS AND BUSINESS ADMINISTRATION (DUEBA)}

Danang University of Economics and Business Administration (DUEBA) is one among five universities and colleges belonging to the Danang University. The total staff of DUEBA is about 200, with 8 faculties, offering training in various subjects in economics. Undergraduate enrollment is approximately 3,000 per year, while the number for graduate and post-graduate students is around 150. In addition, the university also conducts part-time training programs. A majority of students come from the Center region and $40 \%$ come from Danang City itself.

The most important contribution of DUEBA is being a hub for training human resources for the local region. The university also supplies training services for high17 
level local administration. In particular, the university prepared and imparted two-thirds of the courses in the training program for firm directors, which was organized by Danang City as part of a national program run by a consortium of all economics and business administration universities. About 50-60\% of university graduates work in Danang and neighboring provinces, $10-15 \%$ in HCMC, and $10-15 \%$ in the Central Highland located to the west of Danang City.

DUEBA also supplies contract-based training, consulting and other services to enterprises and other organizations in the city and region. In cooperation with the Mekong Project Development Facility (MPDF), an IFC run program to develop private entrepreneurship for the Mekong region, the external training unit of the university is responsible for operating the "Management Development Program," an initiative which aims to help SMEs to hone their management skills and expertise. In addition, DUEBA encourages its staff to cooperate with firms through management consultancies, attention to legal problems, etc.

Apart from training, the university does some research with funds provided by the city to meet local needs. These have included, for example, development of a master plan for tourism in the region and a project to promote a tourist road in the Center region. This source of finance accounts for about $10 \%$ of total research funding for the university. Other DUEBA research projects are funded by the Ministry of Education and Training.

Some large enterprises in the region, like the Danang Electricity Company, have been long-term and close partners of the university. Interestingly, the university does not require any financial contribution from staff working on contracts with firms, but in some 
cases creates favorable conditions (like reducing teaching workload) for them to implement contracts with firms. A total of 132 projects have been implemented by the university over the last few years, of which $68 \%$ were for outside contracts. In addition, firms improve their management capability via various training workshops and seminars on policy and market analysis subjects. In 2001, to formalize its support for firms, DUEBA created the Center for Consultancy and Enterprise Support. In addition to consultancies, the Center supplies tailor-made training programs, organized on an annual basis, for firms working in industries such as brake-manufacturing, oil and gas, airline services, environmental management, coffee, leather and shoes.

Generally speaking, however, the linkages between DUEBA and local firms are still limited. There are several factors influencing this process. Conventionally, DUEBA always regarded teaching as its most important mandate. Other activities are deemed less important and to a large extent are being neglected. Moreover, with a large number of students in full-time training courses, sideline training activities for firms tend to emerge only on an occasional basis. The firms themselves do not have great confidence in the capability of the university system to support technology transfer ${ }^{8}$. Furthermore, in the context of weak competitive pressures, not all firms in the region face the urgent need for innovation and learning. Yet, with increasing competition coming from international integration during the last few years, more firms are recognizing the need for innovation and technology upgrading.

With regard to the policy environment, the DUEBA lacks funds for further commercializing research results or doing pilot projects. In general, no entrepreneurial culture has existed in the university, and DUEBA shows some resistance to engagement 
with outside business. Given these factors, and the needs of the local economy, DUEBA tends to stick to teaching activities.

Local government has created some favorable policy frameworks for linkages between the university and firms. The Danang City authority is well known for its openness and dynamic leadership. GDP growth of the city is well beyond the average nationwide and the city has become a hub for attracting domestic and foreign investment as well as for heritage tourism. Taking advantage of these circumstances, city leaders launched a strong campaign to turn the city into an ideal environment for attracting business and investment, emphasizing the lack of crime as well as the city's cleanliness and good governance. The city allows and indeed encourages universities to recruit new and young talent from all over the country, providing special material incentives like housing and special financial packages, including salary rates above the regulated ceiling. By doing this, the city has kept its own talent at home, and even attracts new people from other big cities like Hanoi or Ho Chi Minh City.

Danang City's Department of Science and Technology (DOST) has received financing from both the MOST and the city government to carry out various technology application programs. DOST calls for strong support from DUEBA staff in providing business skills for enterprises, which are cooperating with DOST in applying new technology. Several initiatives have been taken by the city government to spur innovation and facilitate the use of the knowledge pool created by its local university. The city plans to set up a technology and incubator system, building on the experience of the last five years during which Danang Software Park has been in operation, attracting 
more cooperation from the university. For DUEBA, entrepreneurship training programs initiated by the city government are beginning to have positive effects.

\section{HO CHI MINH CITY UNIVERSITY OF TECHNOLOGY (HCUT), UNDER HCMC NATIONAL UNIVERSITY}

Ho Chi Minh City University of Technology (HCUT) was established in 1957. Today it features five faculties and many centers, with a total staff of 1,112, including 441 lecturers (of whom 51\% hold postgraduate degrees), and 46 professors and associate professors. Full-time student enrollment increased from 2,350 in 1999 to 4,138 in 2003, while part-time students totaled 1,061 and 1,111 respectively.

The most important contribution of HCUT is still in training of human resources. In addition to its mandate to train students, HCUT has a Center for Research and Training Support in Business Administration, and a Consulting Office for Enterprises to link the university with firms and other organizations in the entire country. Both of these entities aim to impact the local economy through multiple channels, including:

1. Educating the workforce at various levels (engineers, workers, technicians), including some opportunities for postgraduate training.

2. Design and orientation of new industries via projects or programs suggested by cities and provinces.

3. Solving specific technical problems of production and business operation in firms, technology transfer and services. 
4. Supplying various kinds of consultancy services in R\&D, testing, standardization, metrology, quality control, and other technical solutions.

HCUT conducts those activities based on agreements with firms to implement cooperative programs and projects, or on close relationships with business associations such as the Plastics Association, Automation S\&T Society, Mechanics Society, and the Association for Leather and Shoe Industry. Many large-scale state-owned enterprises in such industries as garments, plastics, mechanical engineering, construction, brewery, or seafood processing have become long-term partners of HCUT and benefited substantially from this partnership. One important feature of HCUT is its close collaboration with many foreign companies operating in Vietnam. As a first step toward joint R\&D activities, a number of Japanese companies have collaborated with faculty of mechanical engineering, assisted in some equipment and training in design, or computer engineering in research to develop CAD/CAM software.

HCUT has a shareholding company - BackKhoa construction - to act as the commercial arm for its research and training in selected areas. The annual state budget for R\&D and pilot industrial production was about 10 billion VND (around US\$700,000). In the meantime, earnings from technology transfer was 55 billion VND (US\$3.6 million) $)^{9}$. To serve the needs of not only HCMC but also of the Mekong River Delta, HCUT staff is involved in many research projects specifically aiming at the need of the delta.

HCUT is located in Vietnam's most dynamic region of business and the university staff have this advantage in applying new knowledge for economic purposes. The university maintains close relationships with local firms and other organizations, and as a 
result has contributed significantly to production and business activities in HCMC and other provinces in the Mekong River Delta. Most projects for technology transfer are related to agriculture production.

So far, the policy environment is not sufficiently conducive to facilitate technology transfer and market transactions between universities and their potential clients. Inconsistent and contradictory policies and institutional frameworks still create difficulties for universities and firms to work together. Overall management mechanisms for R\&D and IPRs provide little incentive for university staff to work more closely with firms. The establishment and operation of a technology transfer office or other forms of commercial units within the university system so far is not a widely accepted practice and depends on the initiative of each university. Lack of support in terms of funding, training and connection for this necessary institution tends to slow down interactions between universities and others actors. The role of individual scientists, inventors, managers and entrepreneurs has so far received inadequate attention. The lack of an entrepreneurial culture in the university system is a key constraint limiting the contribution of university entrepreneurs to business operations.

Nevertheless, local government is quite active in promoting technology transfer and enhancing the role of the university. The Ho Chi Minh City leadership is the most dynamic among local authorities in Vietnam in creating a supporting mechanism for innovation in research institutes, universities and their links with industry. The city has set up a university council with the participation of many leading research institutes, companies and universities to give advice on how to promote training and innovation, and for linking them closer to the needs of urban development. The city creates programs 
for linkage, enhancing the triangle of "enterprises-local government-university and research institutes," and this supports design, manufacturing, and production of new technology for the modernization of key industries. To assist firms, the city attracts university staff to work in newly established centers of excellence. For example, it created a center called Neptech as a hub to design and manufacture new technology for firms. The city government in coordination with its Department of Science and Technology has introduced an action plan, "Program 04," to develop new technologies appropriate for its needs at reasonable cost, mainly relying on the efforts of domestic research and innovation organizations. The program has been a powerful impetus for HCUT to collaborate with enterprises. Another initiative has set up a list of the so-called key products for the city and mobilized resources of research institutes, firms, universities and associations in a concerted effort to produce these goods. The leadership of HCMC authority has introduced significant measures to strengthen enterprise performance and connections with universities working in the city. In fact, many other provinces and cities now are studying this model carefully in an effort to replicate its success.

\section{CAN THO UNIVERSITY (CTU)}

Can Tho University was established as Can Tho Academy on March 3, 1966 with a mandate to work in such fields as agriculture, veterinary medicine, irrigation, agricultural mechanical engineering, and agriculture economics. The main functions of the CTU are undergraduate, graduate and post-graduate training, as well as research and technology transfer for the Mekong River Delta. Currently, the university has seven 
faculties, three research institutes and three centers with 1,100 staff, of which 735 , or 68.7\%, participate in teaching and $\mathrm{R} \& \mathrm{D}$ activities.

During the period 1985-1992 the university launched a series of new science and technology centers to promote linkages with development in the delta. Annually, CTU receives about 21 billion VND (US\$1.4 million) from various sources for scientific research and technology development activities. CTU benefits from extensive networks that facilitate cooperation with international associations, societies and firms around the world. This helps the university upgrade its infrastructure, facilities, capabilities and knowledge base, and has given rise to various fellowship exchange programs. CTU has 27 cooperative projects with foreign and international organizations, the budget for which totals roughly $\$ 6$ million.

Concerning its main training mandate, CTU is the sole university in the Mekong River Delta and has made crucial contributions to skill development not only for Cantho city, but also for all provinces in the region. Since the 1980s, the university has forged partnerships with provinces in the Mekong River Delta to organize part-time programs to provide university degrees in almost all provinces. In 2004 no fewer than 6,000 students graduated, a majority of whom specialized in applied sciences aimed at serving the needs of farmers and agricultural production in the region. The number of graduates at the master's level increased as well, nearly doubling from 44 in 1996 to 82 in 2004. Most master's students are staff of local government organizations, research institutes, universities, and enterprises in the region, and their research has focused mainly on issues concerning the socio-economic development of the region. These encompass fields such as agriculture, forestry, aquaculture, veterinary medicine, biology and environmental 
management. Significantly, however, the content and quality of training is of some concern among university staff.

Apart from training, CTU is also involved in various fields of scientific research and technological development. These are primarily applied projects in agriculture, biotechnology and aquaculture. Among the notable successes of the CTU in this area are the project on rice varieties research (with more than 30 new types of rice having been approved as national varieties), suitable farming system project, technology transfer for pig farming, agro-based food processing, biotech for agriculture and the production of various types of aquaculture products like shrimp artemia and new breeds of fish. Supply of services for agricultural needs is also a widespread practice of the university. In 2004 alone, there were 39 cooperative projects with provinces. In addition, the university has implemented 19 projects of technology transfer in agriculture and rural development. To commercialize and pursue these activities, CTU has established units like the Company of Plant Protection and the Laboratory on Tissue Culture.

There are not many large-scale industrial firms in the region. Farmers, with their small-scale and family-based production, are the main users of innovation and technology transfer from the CTU. These transfers are often done through farmers' groups or following the guidance of local government at the provincial and district levels. The most significant impacts are job creation and formation of new business opportunities. Along the coast of three provinces, Soc Trang, Bac Lieu and Ca Mau (the furthest southeast provinces of the country, facing the South China sea), technology transfers from CTU enable farmers to combine planting and raising shrimp artemia together with salt production, and to increase crops and productivity in catfish production. 
Unlike other universities, CTU aims primarily to serve the needs of farmers having very low purchasing power, and thus derives limited revenues from commercialization of research. This raises a need for strong government support for technology transfer. So far, most commercialization measures of CTU have to be done via central or local governments, which have budgets for various programs to support farmers. Nevertheless, it is widely believed that policy so far has not been supportive enough for the university to play a better role in this agriculture-based region, whether in training or in technology innovation and dissemination.

Despite the recent efforts of many institutions to bridge university activities and the needs of farmers ${ }^{10}$, long-term planning and strategic orientation are needed. So far, technology transfers from CTU to the region tend to have immediate but only short-term effects. Products from these technologies mainly serve the domestic market and lack international competitiveness. Even in the domestic market, some products cannot compete with imported goods from Thailand or China.

To address these challenges, CTU is adopting a proactive approach by developing longer-term planning via partnership with regions in the development triangle of HCMCBienHoa-Dongnai and Vungtau. Aiming at the niche of agriculture services, the university also contemplates diversifying into other areas of training and research, such as tropical medicines. To overcome investment and financial constraints, CTU is in discussions with provincial authorities and the central government to set up regional high-quality training centers, which aim to constitute a workforce with a more flexible mode of operation and accreditation. These centers might provide practical programs for engineers, community colleges, and so on. Local authorities do play an active role in 
working with CTU. The university is working closely with the Department of S\&T and local government in several provinces to design and implement coherent action plans to support rural and agricultural services for farmers.

\section{THE ROLE OF VIETNAMESE UNIVERSITIES: TRENDS AND CONSTRAINTS}

The main contribution of Vietnamese universities has been and will for some time remain the training of human resources for local economic development, targeting the needs of firms and other organizations. Most universities perform this task rather well in terms of quantity but are often lacking in terms of quality. It is in any event through the supply of human resources, rather than through start-ups and job creation, that Vietnamese universities contribute significantly to the development of local areas. There is little contribution in terms of innovation in local firms, and the clustering effect of innovation from the universities for local economies is therefore insignificant. The socalled spillover impacts of universities remain highly limited in scale.

Having said this, we do find instances of innovation and learning spawned by the university system. Though incremental and minor in nature, these experiences suggest that training is not the sole mechanism through which universities can benefit firms and local productive units. Most universities are involved in consultancy activities, supplying various kinds of services to local productive units, firms or farmer households. Universities offer minor technical improvements that serve demands for import substitution or that address specific needs in the areas of tropical climate production and socio-economic development. Yet there has been no major technological breakthrough by universities, and their role in upgrading the technological level of production in the 
country is still limited, far below that of research institutes under line ministries or of firms themselves.

As for enterprise level perceptions of university-industry linkages, firms widely cite a desire for greater cooperation and assistance from universities and $R \& D$ organizations. Unfortunately, this demand has rarely been met. Local firms tend to accumulate technological learning from other sources, such as other domestic firms and foreign suppliers and buyers, rather than from local universities. Moreover, the reverse effect of local firms on activities of the universities is also limited. There are many reasons for this. Both firms and universities lack capabilities for negotiating with one another, for learning and for sharing information, and for absorbing new knowledge. Many transactions between productive units and universities are based on informal and personal relationships, as the institutional mechanisms to facilitate this process are rarely in place. A further problem is that the overall structure and dynamism of markets do not sufficiently encourage firms to innovate. There is not enough pull for university staff to pay more attention to innovation and serve the firms.

Although the overall picture of the role of universities in innovation and services providers is not encouraging, some key universities have exhibited more dynamic behavior, better performance and interaction with local firms and have been able to induce technology development. Different universities have performed differently in the same macro-policy environment. HCUT located in a large urban area and CTU in a region living on agriculture are examples of the potential for universities to propel economic activities in their respective locations. 


\section{POLICIES, INSTITUTIONAL FRAMEWORKS AND RECOMMENDATIONS}

The overall policy environment in Vietnam is not always conducive to the development of UILs, but cities and other levels of local government can strengthen ties in specific contexts. HCUT benefits from being located at the center of the country's economy -- HCMC alone supplies more than half of total GDP, with a GDP per capita of nearly US\$5,000, or ten times the national average. CTU, in turn, enjoys a unique position in the principal rice producing region of the country, the Mekong River Delta. This suggests that the general context of socio-economic activity in any given locale shapes the actions and performance of the universities. But more than that, university leadership emerges as an important factor in determining whether universities adopt a proactive approach. Adjusting their strategies to very diverse local contexts, university managers can deploy their talents and leadership skills to address economic needs. The case of DUEBA, for example, reveals that even in a less dynamic economic environment, university leadership combined with effective city leadership can have an impact. HUT, in turn, has relied on the dynamism of its own senior administrators to move forward in a context where the capital city government seems to be lagging behind. The HUT leadership is no less entrepreneurial than that of the HCUT, but achieves less success as it faces a less hospitable external environment.

As for factors hindering or supporting university-industry linkages, the institutional framework for urban development policies, and more specifically the incentive policies put in place by local government, emerge as crucial. In those cities where local governments have more liberal and open policies -- like Ho Chi Minh City or Danang -- universities tend to work more closely with firms. Hanoi institutions lack 
the support of municipally-funded innovation initiatives such as Program 4 in HCMC. Individual leaders who champion innovation also have some role to play ${ }^{11}$. Danang city has also made important strides through its forward-looking campaign in cleaning up the city's image. In the case of Hanoi, by contrast, the city government is experimenting with new strategies to a far more limited degree and only slowly, sometimes causing confusion and difficulties for both the city's firms and its universities.

There is a range of policies that need to be improved for facilitating linkages between universities and local firms. Financial constraints and the shortage of a new generation of university staff merit especially focused attention. Incentives need to be extended to enable university research to become more market driven and thus to better serve the needs of firms and industry. It is only through long-term vision that universities will become key actors in the overall innovation system in the country.

In contrast to universities in most of East Asia, the university system in Vietnam originated in the context of a Soviet model that separated teaching from research. This image of the universities has begun to change only in the last 10 years or so, during which attempts have been made to make them more oriented to research and innovation. Today Vietnam's universities are contributing significantly to the development of the country, chiefly through teaching, which is the main business of the universities at this juncture and will remain so for many years to come. But even here important shortcomings need to be overcome: under-qualified lecturers, low quality graduates and poor infrastructure and curricula continue to plague much of the system. As growing competitive pressures require firms to sustain increasingly high levels of technological 
development, the university system will be called upon to supply more qualified human resources for more innovation-intensive activities.

Several clear policy recommendations emerge from this assessment. First and foremost, priority must be given to increasing the quality of training activities throughout the higher education system. Beyond this, longer-term vision and a strategic approach should replace short-term planning aimed at earning fees and securing other benefits for the university system. To overcome the separation of research and teaching, universities should have more autonomy and stronger incentives to encourage innovation research. Investment should be more selective to avoid waste of resources and fragmentation. Modern university management techniques, such as peer review, international advisory committees and performance-based evaluation for both R\&D and teaching quality should be thoroughly applied. The internationalization of the university system -- hiring more international staff and achieving internationally competitive salary levels and management techniques -- as well as rigorous evaluation criteria and a greater emphasis on teaching quality—could create a push for more competition and quality. The model of private universities built as centers of excellence ${ }^{12}$ with social responsibilities might be a sensible option for the country.

Balancing the need for commercialization of research, teaching and serving the public needs is not an easy task for universities in any economy. Establishment of companies to act as commercial arms or TTO, TLO would seem to be appropriate given Vietnam's circumstances. To develop technology markets is one of the central tasks of the increasing linkage with production. These and other new mechanisms should be based on the overall principle of moving in the direction of a market economy, with the 
state focusing on macro-level regulations. This should be seen as a long-term process, requiring determination and flexible solutions for each specific circumstance.

Policy makers should pay attention to both quantitative and qualitative aspects of university-industry linkages. Priority should be given to enhancing the capability of university staff through financial and other incentives, as well as to the organization of the R\&D system, IPR issues, and evaluation of research results. At the same time, a key challenge is to increase the capability of universities to meet the technological innovation needs of enterprises. Although much remains to be accomplished, progress is being made in molding university behavior in more business friendly and innovation-oriented directions. The result may be that Vietnamese universities will develop more productive patterns of interaction with firms and with local economies. 


\section{REFERENCES}

Asian Productivity Association (2003) Asia-Pacific Productivity Data and Analysis 2003.

Tokyo.

Bezanson, K, Tran Ngoc Ca and Oldham, J. (2000) A Science, Technology and Industry

Strategy for Vietnam. UNDP/UNIDO, Hanoi.

Do Huu Hao (2000) Knowledge for industrial development. Proceeding of the conference Using knowledge for development. Hanoi 1998. World Bank and NISTPASS.

Do Dinh Thuan (2000) Using knowledge for agriculture and rural development. Proceeding of the conference Using knowledge for development. Hanoi 1998. World Bank and NISTPASS.

General Statistics Office (2004) ) The Real Situation of Enterprises, Statistics Publishing House, Hanoi.

Lall, S. (2002) Failing to Compete: Technology Development and Technology Systems in Africa, Cheltenham, Northampton, Edward Elgar Publishing Ltd.

Miehlbrandt, A. and InvestConsult Group (2002) Business Development Services in Viet Nam. A Study to Assess the Market for BDS among 1,200 Small and Medium Enterprises in Ha Noi, Ho Chi Minh City, Da Nang, Hai Phong, Dong Nai and Binh Duong. GTZ, VCCI \& Swisscontact, Hanoi, June.

Ministry of Education and Training (MOET) (2005), Data on Education and Training. Website: http://www.edu.vn/data/

National Institute for Science and Technology Policy And Strategy Studies (NISTPASS) (1997) Survey of technological capabilities in seven industries. Hanoi. 
NISTPASS (2000) Research and postgraduate training. Report of RAPOGE project Hanoi.

NISTPASS (2004) Reforms of R\&D policy in the context of transition to market economy. Agriculture publishing house. Hanoi.

Nguyen Quang Thai (2000) Vietnam's Development Strategies and The Role of Knowledge. Proceeding of the conference Using knowledge for development. Hanoi 1998. World Bank and NISTPASS.

Nguyen Vo Hung and Nguyen Thanh Ha (2004) Survey on innovation activities of firms with domestic investment. Report to the project Improving technological capability of Vietnamese industries in transition to market economy. NISTPASS-SIDA/SAREC Pham Minh Hac (2000) Education and human resources. Proceeding of the conference Using knowledge for development. Hanoi 1998. World Bank and NISTPASS.

Service-Growth Consultants Inc., Thien Ngan (Galaxy) Co., Ltd. (1998) Business Services in Vietnam, Private Sector Discussions, Number 5, Mekong Project Development Facility.

Scholtès, P. (1998) Business services and institutional support for industrial development in Vietnam. ASEAN Economic Bulletin; Vol. 15, No. 2, p. 184.

Tran Ngoc Ca (2002) Learning Technological Capability for Vietnam's Industrial Upgrading: Challenges of Globalization. The European Institute of Japanese Studies at the Stockholm School of Economics, Working Paper 165.

Tran Ngoc Ca (2005) Impact of Policy on Development of E-Commerce in Vietnam. Ecommerce in the Asian Context: Selected Case Studies. Edited by Renald Lafond and Chaitali Sinha. IDRC. ISEAS. Singapore. 
UNDP (2004) Millennium Development Goals in Vietnam. Hanoi.

UNDP (2004) Human Development Report Statistics.

UNIDO (1999) Vietnam Industrial Competitiveness Review. UNIDO/DSI Ministry of Planning and Investment, Hanoi.

\footnotetext{
JLuna

$\mathrm{C}: \backslash$ Documents and Settings $\backslash J L u n a \backslash$ Desktop $\backslash$ ca edited version_revised.doc 06/19/2006 11:31:00 AM
}

${ }^{1}$ The main R\&D activities have been undertaken by several groups of institutions, including R\&D institutes under line ministries and National centers for research such as academies. This study focused only on university system.

${ }^{2}$ These are now renamed as Vietnam Academy of Science and Technology (VAST) and Vietnam Academy of social Sciences (VASS).

${ }^{3}$ Racine, J-L. UNIDO, 2004.

${ }^{4}$ Study of the technological capability of firms in 6 industries (NISTPASS-MPI, 1999) and a survey of 319 SMEs.

${ }^{5}$ Student to teacher ratios are about 30 to one, while elsewhere the ratio is about 15 to one.

${ }^{6}$ Data from Tsinghua University (China) show that it has 45 academicians, 929 professors, 1,230 associate professors serving 30,000 undergraduate students, 5,900 graduates and 2,600 postgraduate students. As such the ratio is only 1/9.

${ }^{7}$ A decision by PM to develop technology market aims to address this shortcoming, and was enacted in August 2005. 
${ }^{8}$ This mentality is widespread among Vietnamese industrial enterprises nationwide.

${ }^{9}$ Report of the HCMU in the conference on S\&T activities of the university system. 2004.

${ }^{10}$ One example of these supporting activities is the Ministry of Science and Technology program to support farmers in rural and mountainous areas via science and technology innovation.

${ }^{11}$ The Vice Chairman of the HCMC people committee (the Mayor's office) responsible for international economic cooperation was a Fulbright recipient, former Director of the city Science and Technology Department, and Dean of Technology Management faculty of the HCUT itself.

${ }^{12}$ Tsinghua University is a favorite model for Vietnam as it contemplates how best to collaborate with US universities to build a university that would meet international standards. 